\title{
The golden scale psychology sustainability, algorithm use at a research
}

\author{
Vyacheslav Kazankov ${ }^{1 *}$ \\ ${ }^{1}$ St. Petersburg University of the State Fire Service EMERCOM of Russia, St. Petersburg, Russia
}

\begin{abstract}
The article presents the author's approach to understanding research of a person sustainability. In modern psychology, there is no methodology for numerically assessing human sustainability. The article presents an algorithm for using the scale GSP- $\Omega$. GSP- $\Omega$ - the Golden Scale Psychology Sustainability. Options of use of a scale GSP- $\Omega$ are analyzed. The applicability of the scale GSP- $\Omega$ for different age categories of people, considering their profession and gender, is considered. This scale GSP- $\Omega$ has a high validity for use in assessing the sustainability of a person aged 10 years and older, which is an important factor for a psychologist. The simplicity of scale GSP- $\Omega$ use in different conditions (field and lab) is empirically proved. The article discusses three research hypotheses and briefly describes modern methods for assessing sustainability. The article assumes that the scale can be used by psychologists for different professions. However, she it is most relevant for professions related to stress.
\end{abstract}

\section{Introduction}

D. Jackson, A. Firtko \& M. Edenborough write in work [1] that resilience has attracted the attention of scholars for years; yet, a common definition has proved elusive; much ambiguity continues to exist surrounding the underlying processes that comprise resilience. All research take place in three main directions: psychophysiology, psychology and psychosociology. In psychology operate words "sustainability", "stability", "resilience", "resistance". In Europe and America, psychologists use the words "stability" or "resistance" or "resilience", which translate into Russian as "ustoychivost "', and, conversely, depending on the context [2]. For understanding of material of article, a words "sustainability", "stability", "ustoychivost", "resilience", "resistance", is designated by a uniform symbol $-\Omega$.

C.D. Frith write in work [3] that today the best measurement that psychologists have come up with can vary by nearly $30 \%$ and in comparison, with the "hard" sciences, psychology has had little time to discover what to measure or how to measure it. There is something fundamentally different about the things we are trying to measure. Psychologists use themselves or their volunteers as measuring instruments. These measurements are subjective and as C.D. Frith wrote: "The only way I can know about the things in your mind is because you tell me about them. You press a button to tell me when you see the red light. But there is no way I can get into your mind and check the redness of your experience" [3, p.6]. In time,

\footnotetext{
* Corresponding author: balakhonsky@mail.ru
} 
psychologists will have discovered what to measure and will have developed the instruments that will help us to make these measurements very precisely.

The purpose of the current study is to present for discussion the Golden Scale Psychology Sustainability and her algorithm use at a research. We will designate the Golden Scale Psychology Sustainability - GSP- $\Omega$. Where, sustainability of the person - his ability to maintain health at the psychophysiological, psychological, psychosocial levels of life.

Hypothesis 1. In psychology there is no uniform approach to a technique of assessment sustainability of the person, also, no uniform symbol this term.

Hypothesis 2. The techniques of assessment of sustainability of the person existing in psychology are not suitable for a research at the minimum time of inspection.

Hypothesis 3. The author's scale GSP- $\Omega$ represents itself a versatile tool of a research of sustainability of the person and can be used by the psychologist in different periods of time of a human activity.

\section{Materials and methods}

Stage 1 . The first stage is designed to analyze hypotheses 1 and 2 and identify common weaknesses in existing methods for assessing human sustainability. The scientific sources containing information on terminology and methods of a research sustainability of the person was provided in bases Scopus, Web of Science (WoS), Web of Knowledge (WoK) and other analogs are taken as a basis of the analysis. Search of scientific sources was carried out on meeting in terminology and methods of a research of keywords: "sustainability", "stability", "resilience", "resistance", "psychology", "person". By results of the analysis of sources, the main directions and methods of a research, the analysis, diagnostics, development, and correction sustainability of the person were stated.

Stage 2. The second stage is intended for verification of hypothesis 3. B.S. Okenab, I. Chaminea, W. Wakeland indicate in the article [4, p.146] the following: "A human is a dynamical system composed of subsystems that help maximize utility of the organism. Utility may be defined: (1) from a purely biological perspective such as immediate reproductive success or obtaining food or (2) from a more complex, perhaps hedonic or longer-term perspective such as longer-term reproductive success, obtaining more resources, gaining group support or enjoying an amusement park ride". In work [5] written that the scale GSP$\Omega$ the ratio of three parts of one whole according to the golden ratio rule: the whole (psychophysiological level $(\varphi=1))$ relates to the greater part (psychological level $(\psi=0.618)$ ), how the greater part refers to the smaller part of the whole (psychosocial level $(s=0.382)$ ). Drawings (fig. 1, 2, 3) and Table 1 in work [5] it is possible to combine in one drawing (fig. 1).

Psychophysiological level is the registration of the physiological reactions of an individual. Through the nervous system through feedback lines, physiological markers are interpreted by in psychic markers. Psychophysiological sustainability is the ability to maintain healthy performance at the psychophysiological level. Psychological level is the registration of emotions and mental states of a person, when a human sustainability is established by psychological markers. Psychological sustainability is the ability to maintain healthy performance at the psychological level. Psychosocial level is registration of the volitional manifestation of the orientation of the labor subject, when human sustainability is registered with social markers. Psychosocial sustainability is the ability to maintain healthy performance at the psychosocial level. Psychophysiological sustainability, psychological sustainability, psychosocial sustainability are functionally connected among themselves by the mental phenomena. 

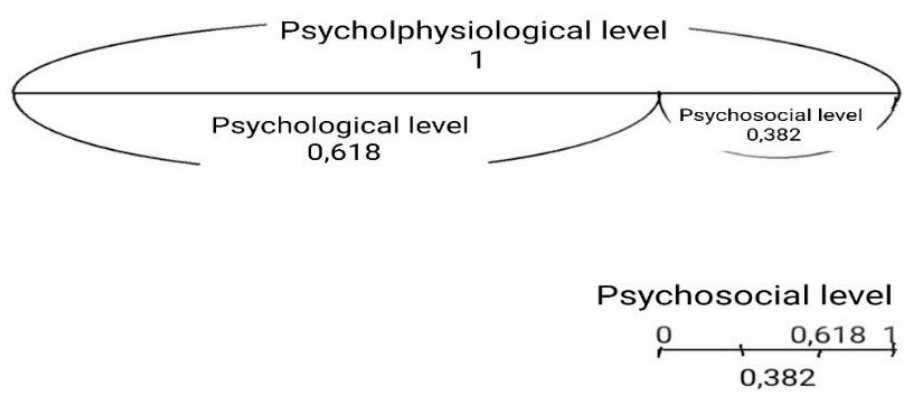

Psychological level

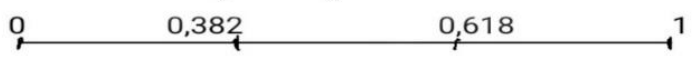

Psycholphysiological level

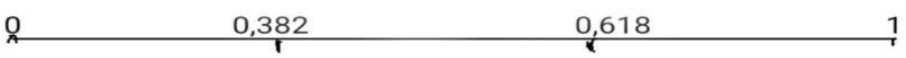

Fig. 1. The psychology of sustainability and GSP- $\Omega$ modifications.

The overall sustainability of a person aged 10 and older can be determined using the scale GSP- $\Omega$ (Fig. 2).

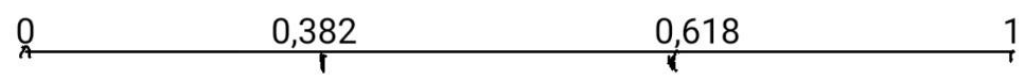

Fig. 2. The scales GSP- $\Omega[5]$.

Where,

From 0.382 to 0.618 - the interval of comfort and human health, the zone of stability.

From 0,382 to 0 or from 0.618 to 1 - the interval of stress and risk, discomfort and vulnerability of a person, the zone of resistance and resilience. From the point of view of sustainability theory, both positive and negative stress lead a person out of the zone of stability, which can affect the appearance of errors in decision-making and subsequent actions.

The interval from 0 to 1 characterizes the sustainability of a person in space and time.

The points 0 and 1 are the points of non-return of the person to the previous state.

The points 0.382 and 0.618 indicate an exit from the stability zone. After therapeutic actions, the person returns to the stability zone with a new reserve of sustainability. This process is called the process of development and improvement of human sustainability in general.

For the respondents of the experimental group (EG), this information is provided immediately. For the respondents of the control group (CG), this information is not conveyed, they evaluate it on the level of intuition, personal experience and available knowledge.

In our scientific and practical work, we claim that the overall sustainability of a person aged 10 and older can be determined using a scale GSP- $\Omega$ (Fig. 2). The scales GSP- $\Omega$ presented in Figure 1 are intended for a more detailed study and are a subsequent study of human sustainability. As you can see, the numerical values of the scales GSP- $\Omega$ are the same, which indicates a unified approach in the study.

An algorithm with limited time. A psychologist gives or draws a scale GSP- $\Omega$ to the respondent and asks to evaluate sustainability: "Numerically estimate your sustainability in the specified interval, where the middle means maximum sustainability." If it is not possible to visually show the scale GSP- $\Omega$, the psychologist can verbally determine the boundaries: 
"Numerically evaluate your sustainability in the range from 0 to 1 , where 0.5 (the middle) means the maximum sustainability."

If there is time and opportunity to communicate with the respondent, the sustainability study is carried out according to the algorithm presented below (Fig. 3).

Working according to the scheme (Fig. 3), it is necessary to take into account the sustainability scheme (Fig. 1), the sustainability model [6], the sustainability matrix [7].

The algorithm shown in the schemes (Fig. 1, 2, 3) can be used once (with a single admission) or repeatedly in different time intervals, collecting statistical data for one patient or a group of patients. Where time,

The upcoming $(\tau 1)$ - characterizes the person's sustainability before entering the situation.

The present $(\tau 2)$ - characterizes the person's sustainability directly in the situation.

The passed $(\tau 3)$ - characterizes the person's sustainability after leaving the situation.

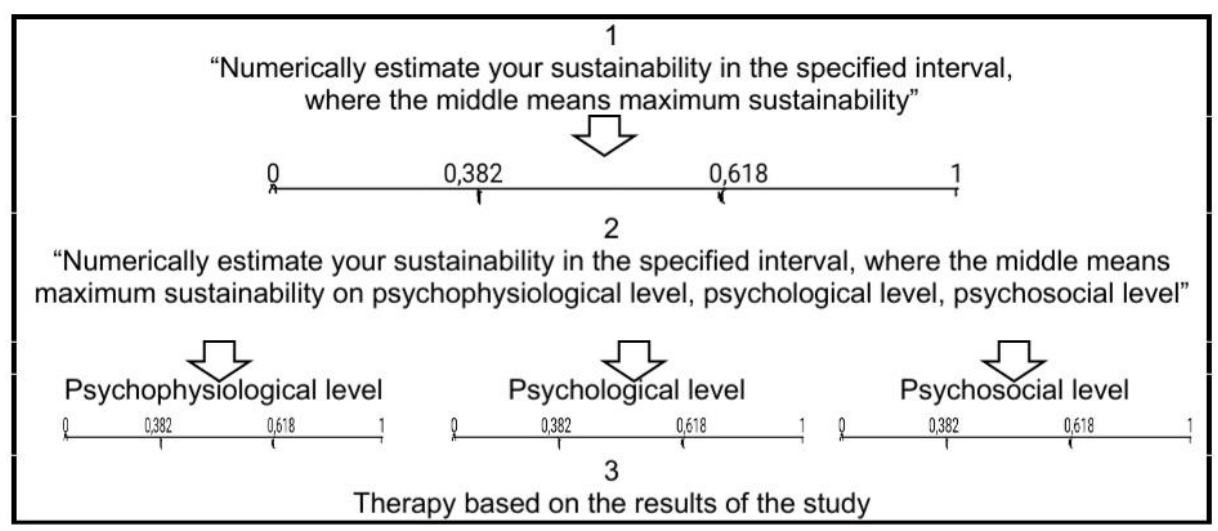

Fig. 3. An algorithm for studying the sustainability from the general to the particular.

We recommend recording the results of the study in the tables (tab. 1 or 2).

Table 1. The psychology of sustainability of the scale GSP- $\Omega$.

\begin{tabular}{|c|c|c|c|}
\hline \multirow{3}{*}{ Name } & \multicolumn{3}{|c|}{$\frac{0,382}{1} \quad 0,618$} \\
\hline & \multicolumn{3}{|c|}{ The point on interval scale GSP $-\Omega$} \\
\hline & $\tau 1$ & $\tau 2$ & $\tau 3$ \\
\hline The conclusion & & & \\
\hline Markers of the sustainability & & & \\
\hline
\end{tabular}

Table 2. The psychology of sustainability of the scales GSP- $\Omega$ modifications.

\begin{tabular}{|c|c|c|c|c|c|c|c|c|c|c|}
\hline \multirow{3}{*}{ № } & \multirow{3}{*}{ Name } & \multicolumn{3}{|c|}{$\begin{array}{c}\text { Psychophysiological level } \\
(\Omega \varphi)\end{array}$} & \multicolumn{3}{|c|}{$\begin{array}{l}\text { Psychological level } \\
\qquad(\Omega \psi)\end{array}$} & \multicolumn{3}{|c|}{$\begin{array}{c}\text { Psychosocial level } \\
(\Omega \mathrm{s})\end{array}$} \\
\hline & & \multicolumn{9}{|c|}{ The point on interval scale GSP- $\Omega$} \\
\hline & & $\tau 1$ & $\tau 2$ & $\tau 3$ & $\tau 1$ & $\tau 2$ & $\tau 3$ & $\tau 1$ & $\tau 2$ & $\tau 3$ \\
\hline \multicolumn{11}{|l|}{1} \\
\hline & $\begin{array}{l}\text { The } \\
\text { conclusion }\end{array}$ & & & & & & & & & \\
\hline & $\begin{array}{l}\text { Markers of } \\
\text { the } \\
\text { sustainability }\end{array}$ & & & & & & & & & \\
\hline$\ldots$ & & & & & & & & & & \\
\hline $\mathrm{n}$ & & & & & & & & & & \\
\hline
\end{tabular}


The validity of scale was studied over 10 years by comparing the results of respondents in a total sample of 1200 people, where 600 people (EG) used scale, another 600 people (CG) did not use it. Each sample consisted of such categories of respondents as graduate students - 150 people, 75 people in each sample; firefighters - 700 people, 350 in each sample; rescuers - 200 people, 100 in each sample; police officers - 150 people, 75 in each sample. The mean age was 31 years. Also, children aged 7 to 11 years were examined in the number of 45 people.

\section{Results}

Stage 1. Definition of sustainability according to questionnaires is offered in most sources. In work [8] written that the Resilience Scale for Adults (RSA) developed by Friborg and Hjemdal, is validated in several countries and is frequently used and validated in a Norwegian population. The items are measured with a seven-point semantic differential scale, with 17 negatively phrased statements and 16 positively phrased statements. The negative statements are reversed before statistical analyses. The higher the score on RSA scale, the more protective factors an individual is assumed to have, e.g., better psychological health, and thus, the individual seems to cope better with adverse life events.

R. Morote et al. write in work [9] about RSA and about the Herth Hope Scale (HHS), she was designed as a multi-facet instrument. The HHS evaluates aspects of particularized hope (time-valued outcome) as well as a generalized sense of transcendence and meaning. Originally, the HHS was designed to measure three aspects of hope (i.e. cognitive, affective and affiliative/spiritual).

J. Arnetz et al. write in work [10] about resilience was measured using an 8-item version of the resilence scale (Wagnild \& Young). Psychological distress was measured using a 9item scale which is a modified version of the General Health Questionnaire (GHQ, Goldberg and Williams). PTSD symptoms were assessed using the PTSD Checklist (PCL, Blanchard et al.; Ruggiero et al.). The PCL contains 17 items which measure the PTSD symptoms listed in the American Psychiatric Association's Diagnostic and Statistical Manual of Mental Disorders. Approach, similar [10], but more difficult on the procedure, is provided in work [11].

In work [12] written about the Brief Resilience Scale (BRS). The BRS is a short six-item measure that assesses the ability to "bounce back" from stress on a five-point Likert scale. In accordance with the original version, the German translation of the BRS consists of six items. The items are rated on a five-point Likert scale.

S. Yasien, J.A. Nasir and T. Shaheen write in work [13] about the resilience was assessed by adult resilience measure by M. Ungar \& L. Liebenberg [14]. Adult resilience scale was designed to assess resources related to individual capacities, relationship with significant persons, belongingness with community, and culture that may intensify their resilience. It consisted on 28-item, divided in 3 subscales (CYRM-28). "The CYRM-28 is designed to demonstrate good content validity within each research site in which it was piloted while still sharing enough homogeneity to make it useful for cross-national comparisons" [14, p.128].

J-S Lee for research sustainability used questionnaires. The number of traumatic events experienced by a participant was assessed using the LEC-5-standard version; Intrusive rumination was measured using the $\mathrm{K}$ version of the ERRI, validated by J. Ahn, and originally developed by C. Cann; Emotional suppression was measured using the $\mathrm{K}$ version of the Emotion Regulation Questionnaire (ERQ) translated by J. Byun and her team; Sense of entrapment was assessed using the Entrapment Scale (ES) developed by Gilbert \& Allan; PTSD symptoms were assessed using the Impact of Event Scale-Revised (IES-R); Perceived social support was measured using the Duke_UNC Functional Social Support Questionnaire (FSSQ), which was developed by Broadhead \& Gehlbach. [15] 
Authors of article [16] offer the scale (RS-11), a shorter version of the original resilience scale [17]. Here resilience is measured by the 11 -item short form (RS-11) validiated by Schumacher et al.. Resilience, in the brief 11-item version, is conceptualized as a protective personality factor that is associated with a healthy development and psychosocial stressresistance, using a 7-point Likert.

Among psychologists $[18,19,20]$ the questionnaire of the Connor-Davidson Resilience Scale (CD-RISC-25) and the simplified its version (CD-RISC-10) enjoys the greatest popularity [21-23]. The CD-RISC-25 contains 25 items. The CD-RISC-10 contains 10 items. The questionnaire of the Connor-Davidson Resilience Scale (CD-RISC) perhaps the most widespread among psychologists of the whole world on a sustainability research.

The presented research methods are designed for the joint work of the psychologist and the patient in a comfortable environment. The time required for respondents to answer the questionnaires is more than 1 minute. The symbol that could be used to denote sustainability is not presented in the works. Also, in the presented articles there is no information on the use of methods in assessing the sustainability of school-age children. These conclusions can be verified by every researcher by studying the submitted scientific articles.

Stage 2 . The results of Table 3 indicate the ability of a person to assess their stability even on the basis of intuitive perception of information. Respondents assessed their resilience in a calm environment. All responses are received within 1 minute. The numerical indicators in Table 3 may cause many psychologists to doubt the reliability of the data presented. Therefore, it is recommended to conduct your research on the respondents that are at the disposal of the psychologist, according to the algorithm described in the article. Table 3 does not include children aged 7 to 9 years, as they could not understand the meaning of the term "sustainability". Therefore, their result is evaluated as 0 . This is due to the difficulty of understanding sustainability. However, after clarification, children aged 10 to 11 years were able to assess their sustainability on a scale (Fig. 1) of up to 1 minute (tab. 3).

Table 3. Assessment by respondents the sustainability.

\begin{tabular}{|c|c|c|c|c|}
\hline & \multirow{2}{*}{$\begin{array}{l}\text { Number of } \\
\text { respondents }\end{array}$} & \multicolumn{2}{|c|}{ Evaluate (could / could not) } & \multirow{2}{*}{$\begin{array}{l}\text { Ratio } \\
(\%)\end{array}$} \\
\hline & & "ro & $\Longrightarrow$ & \\
\hline EG & 600 & & & $100 / 0$ \\
\hline CG & 600 & & & $100 / 0$ \\
\hline $\begin{array}{l}\text { Children (2) } \\
\text { aged } 10 \text { to } 11 \\
\text { years }\end{array}$ & 45 & & & $100 / 0$ \\
\hline
\end{tabular}

Children aged 7 to 11 years were not able to assess separately psychophysiological sustainability, psychological sustainability and psychosocial sustainability (tab. 4). The assessment also caused difficulties for the control group of respondents.

Table 4. Assessment by respondents the sustainability (scales GSP- $\Omega$ modifications).

\begin{tabular}{|c|c|c|c|c|c|c|c|}
\cline { 2 - 8 } \multicolumn{1}{c|}{} & \multirow{2}{*}{$\begin{array}{c}\text { Number of } \\
\text { respondents }\end{array}$} & \multicolumn{2}{|c|}{ Evaluate (could / could not) } & \multicolumn{3}{c|}{ Ratio (\%) } \\
\cline { 3 - 8 } & & $\Omega \varphi$ & $\Omega \psi$ & $\Omega s$ & $\Omega \varphi$ & $\Omega \psi$ & $\Omega s$ \\
\hline EG & 600 & $\mathbf{6 0 0} / 0$ & $\mathbf{6 0 0} / 0$ & $\mathbf{6 0 0} / 0$ & $\mathbf{1 0 0} / 0$ & $\mathbf{1 0 0} / 0$ & $\mathbf{1 0 0} / 0$ \\
\hline CG & 600 & $\mathbf{3 2 5} / 275$ & $\mathbf{4 3 7} / 163$ & $\mathbf{3 0 4} / 296$ & $\mathbf{5 4} / 46$ & $\mathbf{7 3} / 27$ & $\mathbf{5 1} / 49$ \\
\hline Children & 45 & $0 / 45$ & $0 / 45$ & $0 / \mathbf{4 5}$ & $0 / \mathbf{1 0 0}$ & $0 / \mathbf{1 0 0}$ & $0 / \mathbf{1 0 0}$ \\
\hline
\end{tabular}




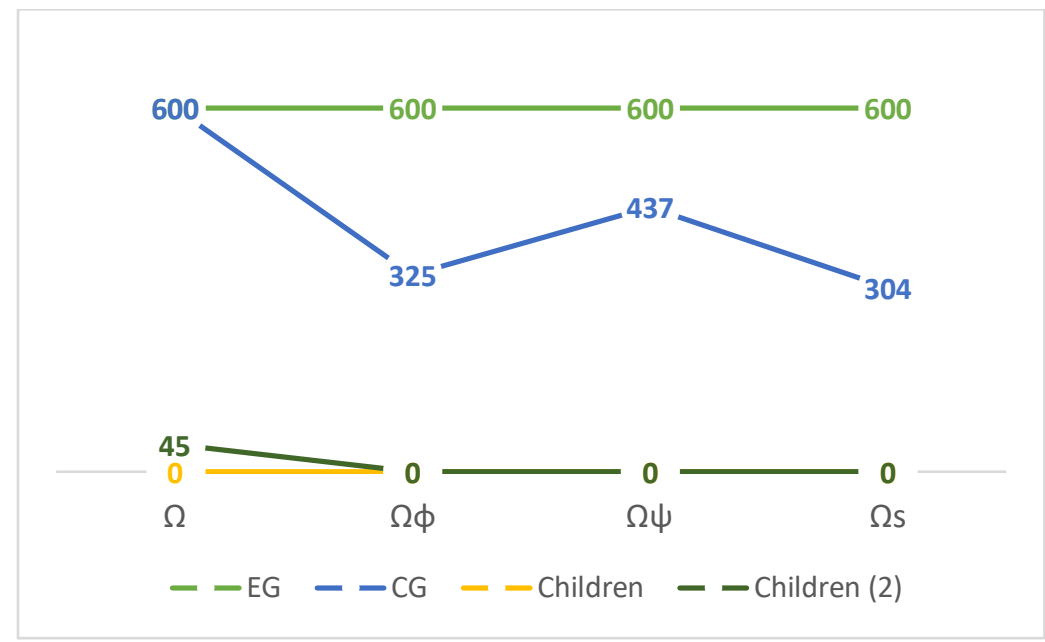

Fig. 4. Visual interpretation of the results of Tables 3 and 4.

\section{Discussion}

The materials presented in the article were obtained by the author in the course of his empirical and experimental research.

The first stage showed. Questionnaires have their advantages, but they are united by an important drawback - the inability to quickly measure the sustainability when the assessment is given less than a minute. This is true for operational services (military, ambulance doctors, firefighters, police officers, rescuers, and others), whose profession is associated with health risks. Also, this is true for all those who are associated with stress in their activities (athletes, managers, negotiators, lawyers, and so on). Due to the complexity of the phenomenon of sustainability, there are difficulties associated with its operational definition and measurement. The second drawback of the methods of assessing sustainability is the age category of respondents, namely, when studying the methods, we did not meet the age category of respondents aged 10 to 15 years.

This confirms hypothesis 1 , in psychology there is no single approach to the methodology of personality assessment, and there is also no single symbol of this term. This confirms hypothesis 2 , the existing methods of assessing a person's personality in psychology are not suitable for research with a minimum examination time (less than 1 minute).

It is important to note that there is no mathematical assessment of sustainability in the articles considered. All the math comes down to the results of the numerical evaluation of the tests. In our opinion, sustainability should have its own specific number. Each person has their own sustainability number at a particular time, but sustainability number lies within the established boundaries. The presence of a number allows you to more accurately assess the sustainability of a person.

The second stage of the study showed. From table 4 and Fig. 4 follows: Firstly, the scale GSP- $\Omega$ is so easy to use that EG respondents were all able to rate their Psychophysiological sustainability, psychological sustainability, psychosocial sustainability, like most CG respondents, even though they rated it intuitively. Secondly, the presented results confirm the claim that most people can appreciate their sustainability and even children from 10 years and older. In both cases, the respondents coped with the task for up to 1 minute. The respondents who have knowledge about sustainability (experimental sample (ES)) and understand the meaning of sustainability intuitively (control sample (CS)) coped with the 
task. We found that when a question about sustainability is asked, the respondent calms down. This effect is under research.

There is no doubt that many may disagree with the presented approach to assessing sustainability of a person by using the developed scale GSP- $\Omega$ and find it too simple and scientifically crude for practical use. However, in psychology there is no alternative solution for a quick assessment of sustainability person, especially in emergency and stressful situations, when it comes to the seconds to make a decision.

The scale GSP- $\Omega$ author's represents itself a versatile tool of a research of sustainability of the person and can be used by the psychologist in different periods of time of a human activity.

We suggest the symbol $(\Omega)$ for psychology of sustainability. The symbol is necessary for mathematical operations with the term sustainability.

\section{Conclusions}

The creation of a fundamental theory of psychology is the most important and at the same time extremely complex problem of modern psychological science. The "Psychology of sustainability" develops its own technologies for assessing, forming and developing the sustainability of the human system. To assess the sustainability, we have developed a scale GSP- $\Omega$. This scale GSP- $\Omega$ can be used by psychologists both in operational activities and in a calm working environment. In our opinion, the scale is reliable and easy to use, as well as sufficiently accessible for explanation and understanding.

In our scientific articles we written about that sustainability man is recommended to understand a person able to maintain health (biological, mental, and social) under the influence of destroyers. In a psychological sense person sustainability is his ability to retain health at the psychophysiological, psychological, and psychosocial levels of life under the influence of destroyers. Destroyers are all that is aimed at damaging and (or) destroying the psychophysiological, psychological, or psychosocial health of a person.

The ideas discussed in the paper should be considered as part of the ongoing work. They are a section of the creative process and are presented here not as a conclusion, but as an example of one of the ways in which new ideas can be nurtured, explored, and to unfold further. The author of the article will be grateful to psychologists who will share their results when using a scale GSP- $\Omega$ designed to assess the sustainability of people of different ages, genders and professions.

\section{References}

1. D. Jackson, A. Firtko, M. Edenborough, Journal of Advanced Nursing, 60 (1), 1-9 (2007) doi: 10.1111/j.1365-2648.2007.04412.x

2. V. Kazankov, E3S Web of Conferences 210, 20020 (2020), https://doi.org/10.1051/e3sconf/202021020020

3. C.D. Frith, Making up the mind: how the brain creates our mental world (First published 2007 by Blackwell Publishing Ltd., 2007)

4. B.S. Okenab, I. Chaminea, W. Wakeland, Behavioural Brain Research 282, 144-154 (2015), https://doi.org/10.1016/j.bbr.2014.12.047

5. V. Kazankov, V. Gubin, E3S Web of Conferences 210, 20018 (2020), https://doi.org/10.1051/e3sconf/202021020018

6. V. Kazankov, E3S Web of Conferences 258, 07004 (2021)

https://doi.org/10.1051/e3sconf/202125807004 
7. V. Kazankov, E3S Web of Conferences 258, 07005 (2021), https://doi.org/10.1051/e3sconf/202125807005

8. H.K. Vegsund, T. Reinfjell, U.K. Moksnes, et al, PLoS ONE, 14(3), e0214138 (2019), https://doi.org/10.1371/journal.pone.0214138

9. R. Morote, O. Hjemdal, K. Krysinska, P.M. Uribe, J. Corveleyn, BMC Psychology, 5, 36 (2017)

10. J. Arnetz, Y. Rofa, B. Arnetz, M.Ventimiglia, H. Jamil, J Nerv Ment Dis., 201(3), 167172 (2013)

11. L. Campbell-Sills, R.C. Kessler, R.J. Ursano, et al, Depress Anxiety, 35(2), 122-131 (2018). doi:10.1002/da.22694

12. A.Chmitorz, M.Wenzel, et al, PLoS ONE, 13(2), e0192761 (2018) https://doi.org/10.1371/journal.pone.0192761

13. S. Yasien, J.A. Nasir, T. Shaheen, Saudi Med J., 37(7), 778-782 (2016) doi:10.15537/smj.2016.7.15004

14. M. Ungar, L. Liebenberg, J of Mixed Methods Research, 5, 126 (2011) DOI: $10.1177 / 1558689811400607$

15. J-S. Lee, PLoS ONE, 14(8), e0220454 (2019) https://doi.org/10.1371/journal.pone.0220454

16. R-D. Kocalevent, M. Zenger, I. Heinen, S. Dwinger, O. Decker, E. Brähler, PLoS ONE, 10(11), e0140322 (2015) https://doi.org/10.1371/journal.pone.0140322

17. J. Schumacher, K. Leppert, T. Gunzelmann, B. Strauß, E. Brähler, Zeitschrift für Klinische Psychologie, Psychiatrie und Psychotherapie, 53, 16-39 (2005)

18. Ö. Karairmak, Psychiatry Research 179, 350-356 (2010) doi:10.1016/j.psychres.2009.09.012

19. D.F. Gucciardi, B. Jackson, T.J. Coulter, C.J. Mallett, Psychology of Sport and Exercise, 12, 423-433(2011)

20. Y. Xie, L. Peng, X. Zuo, M. Li, PLoS ONE, 11(2), e0148843 (2016) https://doi.org/10.1371/journal.pone.0148843

21. L. Campbell-Sills, M.B. Stein, Journal of Traumatic Stress, 20, 6, 1019-1028 (2007), DOI: $10.1002 /$ jts.20271

22. S. Gab-Sik, C. Kyeong-Sook, et al, Annals of Occupational and Environmental Medicine, 30, 52 (2018)

23. C.A. Kermott, R.E. Johnson, R. Sood, S.M. Jenkins, A. Sood, PLoS ONE 14(6), e0218092 (2019) https://doi.org/10.1371/journal.pone.0218092 